
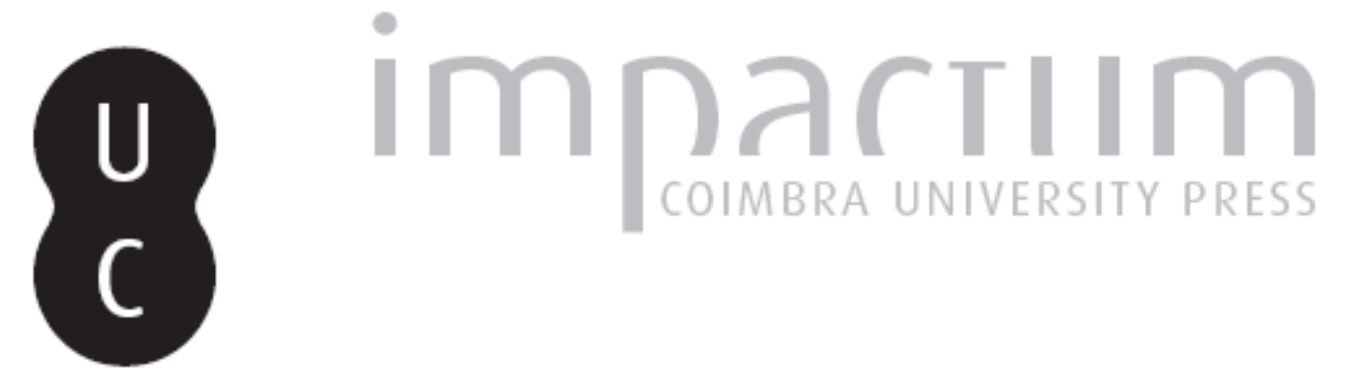

\title{
A produção trovadoresca de Afonso X: 3. Os cantares da guerra (composições e cronologias)
}

Autor(es): $\quad$ Oliveira, António Resende de

Publicado por: Centro de História da Sociedade e da Cultura

URL persistente:

URI:http://hdl.handle.net/10316.2/39359

DOI:

DOI:http://dx.doi.org/10.14195/1645-2259_14_1

Accessed : $\quad$ 26-Apr-2023 14:17:24

A navegação consulta e descarregamento dos títulos inseridos nas Bibliotecas Digitais UC Digitalis, UC Pombalina e UC Impactum, pressupõem a aceitação plena e sem reservas dos Termos e Condições de Uso destas Bibliotecas Digitais, disponíveis em https://digitalis.uc.pt/pt-pt/termos.

Conforme exposto nos referidos Termos e Condições de Uso, o descarregamento de títulos de acesso restrito requer uma licença válida de autorização devendo o utilizador aceder ao(s) documento(s) a partir de um endereço de IP da instituição detentora da supramencionada licença.

Ao utilizador é apenas permitido o descarregamento para uso pessoal, pelo que o emprego do(s) título(s) descarregado(s) para outro fim, designadamente comercial, carece de autorização do respetivo autor ou editor da obra.

Na medida em que todas as obras da UC Digitalis se encontram protegidas pelo Código do Direito de Autor e Direitos Conexos e demais legislação aplicável, toda a cópia, parcial ou total, deste documento, nos casos em que é legalmente admitida, deverá conter ou fazer-se acompanhar por este aviso.

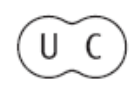




\section{4 \\ 2014}

\section{evista de História da Sociedade e da Cultura}

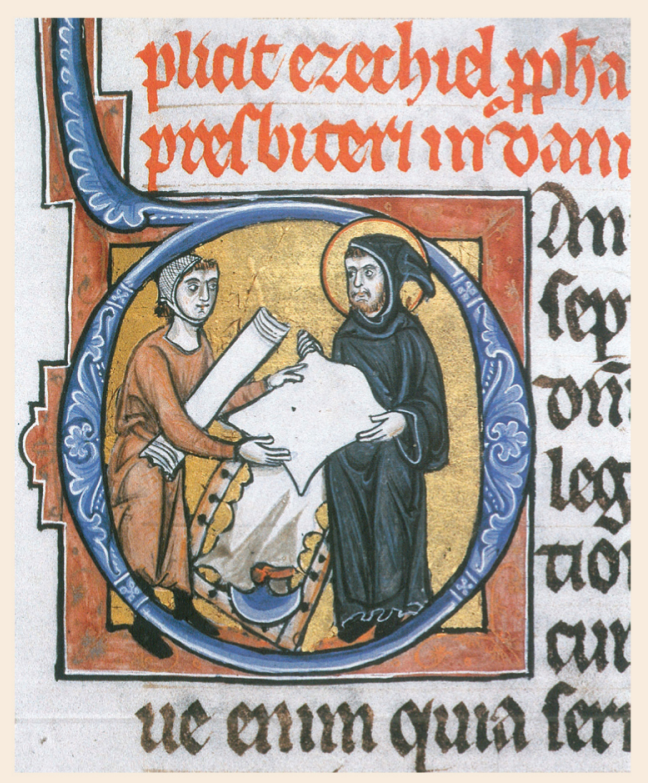

Centro de História da Sociedade e da Cultura Universidade de Coimbra 


\title{
A Produção Trovadoresca de Afonso X: 3. Os Cantares da Guerra (Composições e Cronologias)*
}

\author{
António Resende de Oliveira \\ FLUC/CHSC \\ aresendeo@gmail.com \\ Texto recebido em/Text submitted on: 18.09.2014 \\ Texto aprovado em/Text approved on: 02.11.2014
}

\section{Resumo/Abstract:}

Na obra trovadoresca de D. Afonso X, concretamente na sua produção satírica, sobressaem os cantares que tomam como tema atitudes e comportamentos de diferentes indivíduos ou grupos sociais perante a actividade militar em que o monarca se viu envolvido ao longo do período da sua governação. Este estudo incide, precisamente, na análise do grupo de cantares que tem vindo a ser associado a esta actividade, procurando não só definir com um maior rigor o núcleo de composições de temática guerreira, mas também interrogar-se sobre os conflitos subjacentes a estas mesmas composições, tendo em vista precisar o enquadramento histórico em que terão sido produzidas.

In the troubadour poetry of Alphonso X, namely in his satirical works, the songs about the attitudes and behaviors of different individuals or social groups in view of the military activity in which the king was involved during the course of his reign clearly stand out. This study focuses precisely on the analysis of the group of songs that have been associated to this activity. It attempts not only to define with a greater accuracy the core of works with a war theme, but also to reflect on the conflicts underlying the same works, with a view to clarify the historical background in which they were written.

Palavras chave/Keywords:

Afonso X; Canção trovadoresca galego-portuguesa; Cantigas de escárnio e de maldizer; Sátira militar.

Alphonso X; Portuguese and Galician troubadour songs; Satirical songs; Military satire.

* Este estudo integra-se nas actividades desenvolvidas no âmbito do projecto de investigação La lírica gallego-portuguesa en la corte de Alfonso X. II. - Autores y textos (FFI2011-25899), subvencionado pela 'Dirección General de Investigación y Gestión del Plan Nacional de I+D+i' (Ministerio de Economía y Competitividad espanhol). 
Não foi um reinado pacífico, o de D. Afonso X.

A situação não era nova e deve ser enquadrada no contexto peninsular das lutas da reconquista, que conheciam então um momento decisivo de avanço para sul por parte dos reinos cristãos - em particular do novo reino castelhano-leonês de $\mathrm{D}$. Fernando III -, e conduziram à conquista de Sevilha (1248) ${ }^{1}$. O próprio Sábio, ainda infante, participara ao longo dos anos quarenta neste avanço, estabilizando as perturbações surgidas no reino de Múrcia após a sua entrada na vassalidade castelhana, e participando na entrega de Jaén (1246) e na própria conquista de Sevilha. Pelo meio fizera mesmo uma incursão armada a Portugal em apoio do rei D. Sancho II, que acabara de ser destituído pelo papa ${ }^{2}$. Nos últimos anos de governo do pai a preocupação maior fora a do controle da zona a sul de Sevilha, por intermédio de conquistas ou de acordos com as povoações mais importantes, como Arcos, Medina Sidónia, Vejer ou Jerez, entre outras ${ }^{3}$. Definia-se por então, sem que os intervenientes pudessem ter consciência de tal facto, uma nova situação política que duraria mais de dois séculos e que veria o extremo sul da Península dividido entre duas forças políticas cristãs, Portugal e Castela-Leão, e uma muçulmana, o reino de Granada, última sobrevivência do al-Andaluz. Com a presença próxima das dinastias muçulmanas do norte de África, sempre prontas, em conjunturas propícias, a entrar na Península com o apoio granadino.

1. Nos primeiros anos de governo do Sábio prosseguiu o povoamento e a pacificação da região a sul de Sevilha, com conquistas ou submissão de algumas povoações, e o rei teve de atender também a uma frente de luta

1 Para um balanço sobre a actividade da reconquista nos reinados de D. Fernando III e D. Afonso X pode ler-se LOMAX, Derek W. - La Reconquista. Barcelona: Editorial Crítica, 1984, caps. 6 e 7.

2 FERNANDES, Hermenegildo - D. Sancho II. Lisboa: Temas e Debates, 2010, p. 336-338; VENTURA, Leontina - D. Afonso III. Lisboa: Temas e Debates, 2009, sobretudo p. $90-92$.

3 As intervenções militares do infante D. Afonso não são esquecidas pelos seus biógrafos. Vejam-se, nomeadamente, os capítulos iniciais de GONZÁLEZ JIMÉNEZ, Manuel-Alfonso X el Sábio. Barcelona: Ariel, 2004; e de SALVADOR MARTÍNEZ, H. - Alfonso X el Sábio. Una biografia. Madrid: Ediciones Polifemo, 2003. Um balanço mais sumário encontra-se em RODRÍGUEZ LLOPIS, Miguel - El infante Don Alfonso (1221-1252) in IDEM (coord.) - Alfonso Xy su Época. El siglo del Rey Sábio. Barcelona: 2001, p. 47-65. 
interna submetendo alguma nobreza rebelde na Biscaia, liderada por D. Lopo Dias de Haro. As expectativas imperiais alimentadas a partir de 1256/57 parecem ter travado estas frentes militares, enquanto a documentação dava sinais de projectos para o norte de África, que se materializariam na conquista de Salé em 1260. Foi, todavia, uma conquista rapidamente abandonada e sem quaisquer desenvolvimentos futuros ${ }^{4}$.

Nos começos dos anos sessenta, o relacionamento com os reinos vassalos muçulmanos tomou um novo rumo com as conquistas de Jerez e de Niebla. Tal facto terá estado na origem da revolta generalizada desses reinos, à frente dos quais se encontravam os de Múrcia e Granada, que, com apoio norte-africano, obrigaram a uma actividade militar constante na região andaluza nos três anos seguintes (1264-1266). Do lado murciano, o rei beneficiou do apoio de D. Jaime I de Aragão, que reconquistou o território ao longo de 1265, recuperando a cidade de Múrcia em Janeiro do ano seguinte. Os finais da década de sessenta conheceriam, novamente, algum abrandamento da conflitualidade interna e externa, apesar do regresso dos sinais de descontentamento nobiliárquico. Estes tornar-se-iam mais consistentes a partir de $1272^{5}$, contribuindo, enfim, para as perturbações políticas que marcariam os anos finais do seu reinado.

As acções militares em larga escala voltariam apenas em 1275 com a invasão norte-africana dos benimerines, que manteriam ou tomariam alguns portos, como Algeciras e Rota, devastando regiões do sul castelhano e obrigando o rei a incursões de retaliação, mormente à veiga de Granada em 1281. Deposto no ano seguinte por seu filho D. Sancho, será o próprio rei que se valerá desta tribo marroquina para lhe fazer frente, cercando-o

4 A actividade militar e os conflitos internos no período de governação de Afonso X são tratados nas biografias ou súmulas biográficas recentes, nomeadamente nas de González Jiménez ou de Salvador Martínez, antes mencionadas, ou na de O'CALLAGHAN, Joseph F. - El Rey Sabio. El reinado de Alfonso X de Castilla. Sevilla: Universidad de Sevilla, 1999 (2. ${ }^{a}$ ed.). Numa perspectiva cronologicamente mais alargada, mas centrada na história militar, GARCÍA FITZ, Francisco - Castilla y León frente al Islam. Estrategias de expansión y tácticas militares (siglos XI-XIII). Sevilla: Universidad de Sevilla, 2001, fornece algumas indicações sobre cavalgadas, cercos e batalhas de Afonso X.

5 Apesar de produzida apenas no século XIV, a Crónica de Alfonso X acompanha com cópia de detalhes esta rebelião nobiliárquica. Cf. GONZÁLEZ JIMÉNEZ, Manuel (ed.) Crónica de Alfonso X. Múrcia: Real Academia Alfonso X el Sábio, 1998, sobretudo caps. XX-LVIII (a partir de agora $C A X$, seguido do capítulo em causa). 
em Córdova e fazendo razias até Madrid. O rei marroquino continuará as devastações nos anos seguintes, mesmo após a morte do Sábio. A década final do reinado deste, após a morte do herdeiro Fernando de la Cerda em 1275, seria, assim, um período marcado por intensa actividade militar, quer para fazer frente às incursões benimerines, quer para se opôr, a partir de Sevilha, ao seu filho $\mathrm{D}$. Sancho e à nobreza descontente que se reunira à sua volta, esperando, finalmente, poder resolver a seu favor algumas das reivindicações feitas.

Em conclusão, desde 1243, quando partiu para Múrcia, até à sua morte, ressalvada a segunda metade da década de cinquenta e a década de 1266-1275 , poucos terão sido os anos em que Afonso X não se viu envolvido, directa ou indirectamente, em campanhas militares de caráter ofensivo ou defensivo contra os muçulmanos ou a braços com movimentações de uma nobreza descontente, agrupada à volta de alguns infantes e que esperava as melhores conjunturas para pressionar o rei no sentido de fazer valer as suas pretensões.

2. Alguma da actividade militar do tempo de Afonso $X$ acabou por se reflectir, não só nos cantares de trovadores presentes na corte castelhana, mas também nas composições satíricas do próprio rei ${ }^{6}$. Olhando para o modo como as cantigas do Sábio foram integradas nos cancioneiros - em dois grupos sucessivos identificados pelas rubricas "El rey Don Affonso de Leon" e "El rey Don Affonso de Castela e de Leon" -, é notória a quase ausência do tema no primeiro grupo, que foi associado já, na sua quase totalidade, ao período em que $\mathrm{D}$. Afonso se encontrava ainda na dependência

6 Entre os estudos mais abrangentes sobre o tema lembraria o de VASCONCELOS, Carolina Michaëlis, reeditado em VIEIRA, Y. Frateschi et al - Glosas Marginais ao Cancioneiro Medieval Português de Carolina Michaëlis de Vasconcelos. Coimbra: Universidade de Coimbra, 2004, p. 175-217; o de LAPA, Manuel Rodrigues - Cantigas d'Escarnho e de Mal Dizer dos Cancioneiros Medievais Galego-Portugueses. Lisboa: Edições João Sá da Costa, 1995; e, mais recentemente, acompanhando a edição das cantigas trovadorescas do Sábio, o de PAREDES NÚÑEZ, Juan - La Guerra de Granada en las Cantigas de Alfonso X el Sábio. Granada: Universidad, 1992. Os trovadores portugueses Afonso Mendes de Besteiros, Gil Peres Conde e Pero Gomes Barroso, todos com presença mais ou menos dilatada em terras castelhanas, acompanharam as preocupações régias, como veremos, em algumas das composições satíricas que produziram. 
do pai, apesar de ter participado em múltiplas actividades, mesmo militares, a partir de 1240 .

Embora a guerra, neste núcleo, não assome como tema maior, nota-se, no entanto a sua presença em algumas composições, produzidas em contextos de confronto efectivo ou de tensão e conflito interno. É o caso da bem conhecida cantiga de amigo Ai eu coitada como vivo en gran cuidado ${ }^{8}$, feita quando o então infante veio, nos primeiros meses de 1247, em socorro de D. Sancho II de Portugal, então a braços com a intromissão do Papado na política portuguesa ${ }^{9}$. A referência na cantiga à presença do amigo na Guarda remete para os últimos dias de 1246 ou para Março do ano seguinte, alturas em que o infante terá estacionado perto dessa cidade fronteiriça no percurso de entrada ou de saída do território, no segundo caso levando consigo o rei português, que acabaria por morrer em Castela menos de um ano depois. É ainda o que acontece na tenção em que Garcia Peres interpela o rei - Ũa pregunt'ar quer'a el Rei fazer, começa logo por dizer este trovador sobre o porquê de trazer na corte uma velha "pena veira", coisa seguramente pouco condizente com a dignidade régia ${ }^{10}$. Independentemente do significado desta velha pele colorida de que o rei não parecia querer prescindir, ao justificar o seu uso com "estas guerras [que] nos fazen bulir", insere esta discussão satírica igualmente em momento de efectiva actividade bélica. E olhando para a referência feita a um coteife no mesmo cantar, quase diria

7 OLIVEIRA, A. Resende de - D. Afonso X, infante e trovador. II. A produção trovadoresca. La Parola del Testo. 14 (2010), p. 10-13. O período de juventude do monarca tem sido analisado nas biografias já indicadas. Para além da tentativa de identificação dos cantares feitos pelo Sábio enquanto infante, reavaliei o enquadramento de alguma da sua actividade no mesmo período em OLIVEIRA, A. Resende de - D. Afonso X, infante e trovador. I. Coordenadas de uma ligação à Galiza. Revista de Literatura Medieval. XII (2010) p. 257-270.

8 PAREDES, Juan - El Cancionero profano de Alfonso X el Sabio. Edición crítica, con introducción, notas y glosario. Santiago de Compostela: Universidade de Santiago de Compostela, 2010, I. A partir de agora citarei as composições do Sábio a partir do apelido do seu editor e do número que lhe corresponde nesta edição (neste caso, PAREDES I) ou, para comentários, a partir da indicação de página. Na citação das composições de outros autores remeto para BREA, Mercedes (coord.) - Lírica Profana Galego-portuguesa. 2 vols. Santiago de Compostela: Xunta de Galicia-Centro Ramón Piñeiro, 1996, a partir da sigla LP seguida dos números que identificam o autor e composição em causa.

9 VENTURA, Leontina - D. Afonso III, cit., p. 87-100, para a conturbada situação portuguesa da altura.

${ }^{10}$ PAREDES $X$. 
que a composição poderia ter sido feita não na década de 50, como sugeri já na sequência de outros autores ${ }^{11}$, mas na década seguinte quando, no contexto do levantamento muçulmano andaluz, a documentação se fez eco de dificuldades no recrutamento dos exércitos concelhios ${ }^{12}$.

Neste primeiro núcleo de composições, apenas um cantar parece ter uma ligação mais directa com a actividade militar. Trata-se de Don Rodrigo moordomo que ben pos al Rei a mesa, onde ecoam as dissenções entre o herdeiro e seu irmão D. Henrique, datadas já de 1248-1252 mas que prosseguiram pelo governo do Sábio ${ }^{13}$. Como a composição elogia o mordomo D. Rodrigo, estaremos perante D. Rodrigo González Girón, mordomo de D. Fernando III entre 1238-1246 e entre 1248-1252 e não, como pensaram Rodrigues Lapa e outros autores, perante um qualquer mordomo do infante rebelde D. Henrique ${ }^{14}$. Tal facto obriga a uma leitura do cantar algo diferente daquela que tem sido feita. Atente-se, antes de mais no texto, do qual reproduzo as duas primeiras estrofes:

Don Rodrigo moordomo, que ben pos al Rei a mesa, quando diss' a Don Anrique: - Pois a vosso padre pesa, non lhi dedes o castelo, esto vos digo de chão, e dar-vos-ei en ajuda muito coteife vilão.

E dos poldrancos de Campos levarei grandes companhas, e dar-vos-ei em ajuda todolos de Val de Canhas; e des i pera meu corpo levarei ta[1] guisamento, que nunca en nen un tempo trouxo tal Pero Sarmento

Aparentemente, o mordomo régio preparava-se para apoiar o infante D. Henrique contra o rei, dizendo-lhe para não the entregar o castelo e garantindo-lhe forças militares em apoio das suas pretensões, em clara contradição com o incipit da cantiga, que salientara a qualidade do seu serviço no desempenho do cargo de mordomo. Mas, relendo com mais atenção a composição, começaremos a duvidar da eficácia do apoio que

${ }^{11}$ OLIVEIRA, A. Resende de - D. Afonso X, infante e trovador II..., cit., p. 16.

${ }^{12}$ CAX, cap. XII e nt 39.

13 PAREDES IX.

${ }^{14}$ LAPA, Manuel Rodrigues - Cantigas d'Escarnho..., cit., p. 42; LOPES, Graça Videira - Cantigas de Escárnio e Maldizer dos Trovadores e Jograis Galego-Portugueses. Lisboa: Editorial Estampa, 2002, p. 54; PAREDES, Juan - El cancionero profano..., cit., p. 112. 
o mordomo se preparava para prestar ao infante. Na realidade, a avaliar pelas tropas prometidas - "muito coteife vilão", "gran peça de peões [...] sen lanças" - interrogamo-nos, desde logo, se esta ajuda não seria mesmo a maneira mais rápida de derrotar o infante rebelde e, portanto, mais um elogio à lealdade do conhecido mordomo ${ }^{15}$.

É, no entanto, no segundo grupo de composições do Sábio, aquele que congrega cantares compostos sobretudo durante o período da sua governação ${ }^{16}$, que a guerra adquire uma maior saliência e projecção em virtude da produção de um conjunto de sátiras violentas ligadas a importantes confrontos militares ocorridos durante o seu reinado e que constituem porventura o núcleo mais significativo da sua obra trovadoresca.

Seguindo a sequência com que nos são devolvidas pelos cancioneiros, as duas composições seleccionadas de início apresentam algumas afinidades que me levam a equacioná-las em conjunto. A primeira delas é a identificação dos satirizados, algo não muito comum, como veremos, nos restantes cantares do tema em análise. Na verdade, a primeira cantiga é dirigida aparentemente a um Pero Garcia Galego, nome já documentado, enquanto a segunda visa um D. Mendo de Candarei, talvez um familiar do trovador Nuno Rodrigues de Candarei, identificado no cantar como "amigo de Souto Maior". Uma segunda afinidade resulta das dificuldades em enquadrar ambas as composições no âmbito da actividade militar, apesar de aparecerem habitualmente no núcleo das composições a ela ligadas ${ }^{17}$.

${ }^{15}$ Ter-se-á notado que esta interpretação inverte por completo o sentido que vem sendo atribuído à sátira. Ou seja, o que parece estar em causa na composição, não será tanto, como tem sido sugerido, uma qualquer traição de D. Rodrigo ao ser dever de lealdade para com Fernando III mas, pelo contrário, um sinal do cumprimento superlativo desse mesmo dever, tão importante em contexto feudal, com a oferta de préstimos a um adversário político do seu senhor mas que garantiam a este, desde logo, boas condições para reverter a situação em seu favor. O conhecimento das figuras de Pero Sarmento e Fernando Teles, ambas mencionadas no cantar, e daquilo que podem representar, ajudará, por certo, a um entendimento cabal deste escárnio.

${ }^{16}$ OLIVEIRA, A. Resende - D. Afonso X infante e trovador II..., cit., p. 10-13.

${ }^{17}$ Cf. LAPA, Manuel Rodrigues - Cantigas d'Escarnho..., cit., p. 21-23; LOPES, Graça Videira - Cantigas de Escárnio..., cit., p. 60-62, autora que, no entanto, manifesta dúvidas em relação ao enquadramento das composições relativas a D. Mendo de Candarei; PAREDES, Juan - El Cancionero profano..., cit., nos comentários às composições XVII e XX, p. 153 e 161. 
Na primeira, Pero que ei ora mengua de companha ${ }^{18}$, o rei queixa-se da ausência de Pero Garcia, apesar de necessitar de um maior séquito ou companhia. Atente-se na primeira estrofe - repetida com leves alterações nas seguintes e a substituição de Pero Garcia por Pero Galinha na terceira - e na finda:

Pero que ei ora mengua de companha, nen Pero Garcia nen Pero d'Espanha nen Pero Galego non irá comego.

Galego, Galego, outren irá comego.

Para além da palavra "companha" não implicar necessariamente que estamos perante a preparação de uma qualquer companhia militar ${ }^{19}$, mantém-se a indecisão quanto ao significado a atribuir ao cantar. Nenhuma indicação concreta, por outro lado, parece apontar inequivocamente para as guerras andaluzas dos anos 60, enquadramento em que tem sido situada ${ }^{20}$, sendo manifestamente insuficiente a utilização nesse sentido do jogo entre Pero Garcia/Pero Galinha, enquanto sinal de cobardia que, a ser verdade, se poderia ter manifestado fora desse contexto.

Na segunda composição, Don Meendo, Don Meendo, defrontámo-nos com idênticas dificuldades quanto à sua associação à temática em estudo ${ }^{21}$. O seu sentido decorrerá da interpretação do provérbio "quen leva o baio, non leixa a sela", que surge como refrão no cantar e cujo enquadramento pode ver visto na primeira estrofe:

Don Meendo, Don Meendo, por quant'ora eu entendo, quen leva o baio, non leixa a sela.

18 PAREDES XVII.

${ }^{19}$ Veja-se o enquadramento da utilização da palavra no glossário das Cantigas de Santa Maria em METTMANN, W. (ed.) - Cantigas de Santa Maria. Vigo: Edicións Xerais de Galicia, 1981, t. II, p. 494.

${ }^{20}$ Cf. as obras agora citadas de Rodrigues Lapa, de Videira Lopes e de Juan Paredes. Quanto a Pero Garcia Galego, tratando-se de um membro da nobreza galega, a associação do cantar, feita por Rodrigues Lapa, à ausência dos exércitos urbanos nas guerras de fronteira perde pertinência (veja-se, na p. 21, o enquadramento do cantar feito por este investigador com recurso a um extracto da Crónica de Alfonso X).

${ }^{21}$ PAREDES XX. 
De acordo com a interpretação de Rodrigues Lapa, dependente do que é dito numa segunda sátira a D. Mendo, este, "tendo recebido o cavalo das mãos do Rei, isto é, em sentido figurado, uma boa espórtula para o servir na guerra contra o mouro, tinha deixado a sela, ainda em sentido figurado, pretexto apenas para se não servir dela e não servir o rei”"22. O facto é que a sátira em causa, reduzida a uma estrofe que reproduzimos de seguida, não contém elementos que nos possam ajudar a admitir um eventual enquadramento militar:

Don Meendo, vós veestes
falar migo noutro dia;
e na fala que fezestes
perdi eu do que tragia.
Ar quer[r]edes falar migo
e non quer[r]ei eu, amigo. ${ }^{23}$

Não ressalta, enfim, de qualquer das composições em análise a agressividade que encontramos nas restantes deste ciclo temático. Na verdade, não se vislumbra que o tratamento dado a Pero Garcia seja equiparável ao dirigido a alguém a quem se atribui um comportamento infame, nem que, por outro lado, seja claro tratar-se de um caso de falta ao chamamento para as guerras de fronteira ${ }^{24}$; e muito menos o poderemos inferir das composições de D. Mendo, tratado numa delas como "amigo" e na outra como "amigo de Souto Maior".

Finalmente, o conhecimento dos satirizados conduz-nos a uma terceira afinidade entre as composições: quer um quer outro são originários da Galiza, porventura da região do sul da Galiza, precisamente aquela que Afonso X, ainda infante, terá frequentado com mais assiduidade pelos finais da década de trinta e inícios da seguinte ${ }^{25}$.

${ }^{22}$ LAPA, M. Rodrigues - Cantigas d'Escarnho..., cit., p. 23.

${ }^{23}$ PAREDES XIX. Sobre a dívida do refrão deste cantar para com Pero Garcia Burgalês veja-se LORENZO GRADÍN, Pilar-Accesus ad tropatores. Contribución al estudio de los 'contrafacta' em la lírica galego-portuguesa in HILTY, Gerold (ed.) - Actes du XXe Congrès International de Linguistique et Philologie Romanes. t. V, Zurich: 1992, p. 106-107.

${ }^{24}$ Veja-se, nomeadamente, o enquadramento proposto por LOPES, Graça Videira Cantigas de Escárnio..., cit., p. 60.

${ }^{25}$ OLIVEIRA, A. Resende de - D. Afonso X, infante e trovador I..., cit., sobretudo p. 262-268, no âmbito da reavaliação dos laços que ligavam o infante à Galiza ao longo 
Ora, olhando para estas composições no quadro da obra satírica do Sábio, verifica-se facilmente, pelo tom da sátira, pela identificação dos satirizados e pelo ambiente galego em que terão sido produzidas, que elas devem ser reconduzidas precisamente ao ambiente mais distendido e pessoal dos cantares produzidos pelo então infante herdeiro, e não ao carácter mais impessoal e ao mesmo tempo mais duro que toma a sátira régia a partir dos anos sessenta, perante os graves problemas militares que teve de debelar na sequência da revolta mudéjar.

Tal significa que não encontro nelas elementos credíveis que me levem a ligá-las ao núcleo das restantes composições sobre a actividade militar do monarca a partir dos anos sessenta. A análise dessas composições permitirá concretizar as diferenças mencionadas.

3. Assinaladas as composições em que a guerra assume um papel marginal ${ }^{26} \mathrm{e}$ integradas as duas últimas referidas na produção pertencente ao período anterior a 1252, a continuação da busca das composições atentas às movimentações militares no reino de Castela obriga-nos a deter a atenção em Vi un coteife de mui gran granhon ${ }^{27}$, cantiga cuja primeira estrofe nos elucida sobre o que nela está em causa:

Vi un coteife de mui gran granhon, con seu porponto, mais non d'algodon, e con sas calças velhas de branqueta. E dix'eu logo: - Poi-las guerras son, ai, que coteife pera a carreta!

Ou seja, o Sábio perante a visão de um combatente de fartas barbas e miseravelmente vestido - porventura um peão, pois não é feita qualquer referência ao cavalo -, que se aprestava para entrar em campanha, logo

dos anos trinta e inícios da década seguinte, antes da nova visibilidade por ele adquirida na estabilização da região de Múrcia a partir de 1243. Admitindo que estes cantares se poderiam reportar a uma campanha militar, teriam o seu enquadramento natural numa das operações do infante por estes anos quarenta.

${ }^{26}$ Foram excluídas deste percurso outras composições feitas em contexto militar, mormente na fronteira andaluza, mas cuja vertente satírica não incidia, mais uma vez, sobre a actividade militar propriamente dita. Vejam-se, nomeadamente, os cantares dirigidos a Maria Peres Balteira em OLIVEIRA, A. Resende de-A produção trovadoresca de Afonso X. 1. As sátiras à Balteira. Medioevo Romanzo. XXXVII, fasc. II (2013), p. 379-399.

${ }^{27}$ LP 18,46 . 
pensou em o relegar para os serviços afectos à manutenção do exército ${ }^{28}$. A figura do coteife já tinha aparecido no cantar sobre o mordomo do rei D. Fernando e imaginamos melhor, sem dúvida, o exército que poderia sair daqui para acudir a D. Henrique e enfrentar o exército régio, isto é, um exército de combatentes que o rei procurava evitar que pegassem sequer em armas. Quanto ao resto, a imagem é a mesma, com um retrato a ser construído a partir da ausência de armamento adequado, ou de vestuário e adereços pobres ou desconformes ${ }^{29}$.

Se, como tem sido sugerido, a designação coteife se aplica aos combatentes dos exércitos urbanos - quer ao peão, quer ao cavaleiro vilão $0^{30}$-, quem estará em causa serão precisamente essas franjas do exército régio que, em determinado momento, terão sido mal vistas em âmbito cortesão. $\mathrm{Na}$ verdade, por alguma documentação régia de meados da década de sessenta, sabe-se da existência de atritos entre os concelhos e o rei por causa de alguns tributos, nomeadamente a fossadeira, uma taxa ligada à actividade militar $^{31}$. Deve lembrar-se que, militarmente, se trataria de um momento em que esses combatentes seriam cruciais para debelar a revolta das populações muçulmanas na Andaluzia, pelo que esta cronologia se apresenta como a mais capaz de enquadrar estas composições.

Uma segunda composição, que coloca igualmente em cena o coteife, confirma este enquadramento. Aqui, na primeira e terceira estrofe de $O$ genete,

${ }^{28}$ Sobre o trem de apoio do exército são esclarecedoras as páginas que lhe dedica MONTEIRO, João Gouveia - A Guerra em Portugal nos finais da Idade Média. Lisboa: Editorial Notícias, 1998, p. 252-255. Para a possível alusão neste texto a um episódio de Le Chevalier de la Charrette de Chrétien de Troyes, veja-se LORENZO GRADÍN, Pilar-Lancelot comme toile de fond d'Alphonse X?. Cahiers de Civilisation Médiévale. 51 (2008), p. 143-156.

${ }^{29}$ Relembrem-se, na composição sobre D. Rodrigo, os "peões, todos calvos e sen lanças, e con grandes çapatões" (PAREDES IX) e nesta o "coteife mal guisad' e vil, con [...] o cordon d'ouro, tal por joeta", isto é, com um cordão dourado como adorno. Veja-se uma outra proposta de leitura do verso 13 em LAPA, M. Rodrigues-Cantigas d'Escarnho..., cit., p. 24.

${ }^{30}$ Como refere Piel, a associação ao cavaleiro é bem notória nas Cantigas de Santa Maria (cf. n. ${ }^{\circ} 22$ e n. ${ }^{\circ} 194$ da já citada ed. de W. Mettmann). Cf. PIEL, Joseph-Maria - Coteifes orpelados, panos d' arrazes e martinhos", in IDEM - Estudos de Linguística Histórica Galego-Portuguesa. Lisboa: IN-CM, 1989, p. 118.

${ }^{31}$ Alguns documentos sumariados em GONZÁLEZ JIMÉNEZ, Manuel e CARMONA RUIZ, M. Antonia - Documentación e Itinerario de Alfonso X el Sábio. Sevilla: Universidad de Sevilla, 2012, reportam o problema quer para o período anterior a 20 de Junho de 1264 , altura em que o rei tinha já conhecimento da sublevação mudéjar, quer para o período posterior, onde aparecem outros privilégios resultantes da participação na hoste régia. 
vêmo-lo transido de medo perante os genetes, cavaleiros acabados de chegar de África com o exército que veio em apoio dos revoltosos:

O genete, pois remete seu alfaraz corredor, estremece e esmorece o coteife con pavor

Vi coteifes de gran brio, eno meio do estio, estar tremendo sen frio ant'os mouros d'Azamor; e ia-se deles rio que Aguadalquivir maior. ${ }^{32}$

Agora, a roupa e o equipamento passavam a plano secundário e era o comportamento na batalha que sobressaía, com o pavor sentido perante a velocidade e destreza dos cavaleiros africanos que apareciam na Península, ao que se sabe pela primeira vez, em $1264^{33}$. Mas não foram somente os coteifes que se viram a braços com os genetes. Uma briga muito especial terá sido travada por um deles com Domingas Eanes, provavelmente uma soldadeira, como supõem todos os editores. A sátira régia vai descrevendo o duelo sexual entre ambos, com golpes e contragolpes, e a derrota final da soldadeira, a contas com uma doença venérea. Damos apenas início ao “combate”, com a transcrição da primeira estrofe que dá o tom da sátira:

Domingas Eanes ouve sa baralha com ũu genet', e foi mal ferida; empero foi ela i tan ardida, que houve depois a vencer, sen falha, e, de pran, venceu bõo cavaleiro; mais empero é-x' el tan braceiro, que ouv' end' ela de ficar colpada. ${ }^{34}$

${ }^{32}$ PAREDES XXXVII.

${ }^{33}$ CAX, cap. XIII.

${ }^{34}$ PAREDES XLI. Tratando-se de uma soldadeira, Afonso X, associando-a a um dos famosos cavaleiros chegados de África, integrava mais uma vez esta figura entre as que eram presença obrigatória na zona de fronteira, acompanhando o bulício destas campanhas 
Não sabemos se o rei resolveu, neste caso, recorrer à imaginação inventando esta singular batalha a partir da impressão generalizada causada pelos novos combatentes chegados à Península. Nem sabemos, sequer, quem é esta Domingas Eanes, que surge apenas nesta composição e sem qualquer indicação quanto ao seu papel neste contexto militar, embora a encenação feita e a sua presença na proximidade deste mesmo contexto caucione a hipótese da sua identificação como soldadeira. Mas a presença do genete permite integrá-la neste núcleo de composições de meados dos anos sessenta, momento em que a novidade da integração deste cavaleiro no exército muçulmano poderia ter suscitado o cantar em que figura.

Menos segurança oferece a integração neste mesmo período de Don Foan, quand'ogano i chegou ${ }^{35}$, que retrata um caso de cobardia e deslealdade de quem abandonara o seu senhor na fronteira à sua sorte e tratara de regressar a casa. Atente-se na primeira estrofe:

Don Foan, quand' ogano i chegou primeirament' e viu volta e guerra, tan gran sabor ouve d' ir a sa terra que logu' enton por adail filhou seu coraçon; e el fez-lh' i leixar, polo mais toste da guerr' alongar, prez e esforço, e passou a serra.

Tratar-se-á certamente de um magnate que se afastava da fronteira por um percurso que, passando por Lora (talvez Lora del Río), se dirigia a Talaveira. A referência a ambas povoações na composição é o único elemento concreto disponível, mas não permite retirar grandes ilações quanto ao período em que este acontecimento ocorreu. Atrevo-me, no entanto, a situá-la igualmente em meados dos anos sessenta, tendo em atenção a sua similitude em relação a um cantar de Afonso Mendes de Besteiros que dá conta de uma mesma situação ocorrida nessa altura. Refiro-me a Don Foão, que eu sei que á preço de livão, em que este trovador português presente em Castela assinala

militares. Para algumas composições afins veja-se o ciclo dedicado a Maria Peres Balteira. Cf. ALVAR, Carlos - María Pérez, Balteira. Archivo de Filologia Aragonesa, XXXVI-XXXVII (1985), p. 11-40, e OLIVEIRA, A. Resende - A produção trovadoresca de Afonso X. 1. ..., cit., p. 381-392 para os cantares em causa.

35 PAREDES XXXII. 
idêntica fuga do campo de batalha. Como se depreende do refrão, neste caso tratava-se de um nobre português que, tal como os coteifes, parece ter ficado impressionado com os genetes norte-africanos:

Don Foão, que eu sei que á preço de livão vedes que fez ena guerra - daquesto soo certão: sol que viu os genetes, come boi que fer tavão, sacudiu-se [e] revolveu-se, alçou rab'e foi sa via a Portugal. ${ }^{36}$

As duas últimas composições do Sábio - O que foi passar a serra e O que da guerra levou cavaleiros ${ }^{37}$ - merecem uma primeira aproximação conjunta porque se afastam um tanto do tipo de sátira habitual em âmbito peninsular. Com efeito, ao contrário dos cantares que têm vindo a ser referidos, dirigidos a indivíduos concretos, mesmo que não identificados, serão talvez aquilo a que poderíamos chamar sátiras colectivas, dirigidas a diferentes personagens, também não identificadas mas marcadas por acções consideradas negativas, e que terão ocorrido num mesmo contexto militar ou em ligação próxima com ele. A primeira, em quatro estrofes, explorará quatro casos exemplares de ricos-homens que pretenderiam beneficiar dos rendimentos ligados à prestação do serviço militar sem, no entanto, participarem nas operações programadas e utilizando diferentes subterfúgios para se eximirem a essa obrigação, nomeadamente apresentando-se a desoras. $\mathrm{O}$ rei aproveita o refrão para amaldiçoar esta cavalaria nefasta, com bom faro para se governar esquivando-se aos seus deveres. Exemplificamos com a primeira e terceira estrofes a abordagem régia:

$\mathrm{O}$ que foi passar a serra e non quis servir a terra, e ora, entrant' a guerra, que faroneja?

Pois el agora tan muito erra, maldito seja!

\footnotetext{
${ }^{36}$ LP 7,4.

${ }^{37}$ PAREDES XL e XLII, respectivamente.
} 
O que filhou gran soldada

e nunca fez cavalgada,

e por non ir a Graada

que faroneja?

Se é ric' omen ou á mesnada, maldito seja!

Fica desde logo a sensação de que conhecemos já estas acções de qualquer $\operatorname{lado}^{38}$. A primeira estrofe poderá remeter, por exemplo, para aquele D. Foão cobarde e desleal que o rei tomou à sua conta em Don Foan, de quand' ogano i chegou. Mas o rei poderia conhecer casos similares capazes de suscitar o arranque da composição, que corresponde, no entanto, ao fim da primeira estrofe do cantar agora relembrado. A situação presente na terceira estrofe do cantar em análise poderá aproximar-se de um caso aparentemente idêntico narrado em Quen nunca sal da pousada, de Gil Peres Conde ${ }^{39}$. Este autor português, activo em Castela pelo menos a partir de finais da década de sessenta, critica nesta composição um vassalo do rei ou de D. Fernando, o herdeiro que acabaria por morrer em 1275. E o motivo da sátira radica precisamente no facto de este vassalo, nunca tendo entrado em qualquer cavalgada, beneficiar de uma boa soldada, certamente atendendo à qualidade do seu senhor. Já a segunda estrofe da composição, ao mencionar "O que levou os dinheiros/e non troux' os cavaleiros", relembra inevitavelmente a primeira da composição que analisaremos de seguida. Por outras palavras, estas aproximações, dadas as dúvidas que permanecem, envolvem-nos num dédalo de incertezas do qual será difícil sairmos no sentido de tentar situar e enquadrar as composições que as suscitam.

$\mathrm{Na}$ verdade, O que da guerra levou cavaleiros, a segunda composição em estudo, exponencia a composição anterior transformando-se num vasto painel, diríamos, um políptico em que o Sábio explora, em 15 quadros, outras tantas situações onde se reitera a crítica a comportamentos ligados à guerra, cuja menção vai pontuando a narrativa. A conclusão é sempre a

${ }^{38} \mathrm{O}$ terceiro verso tem levantado problemas de interpretação em virtude do papel a atribuir à particula $e$. A questão será saber se se trata de uma conjunção ou de uma forma verbal (é). Paredes resume várias propostas nas p. 275-276. Lapa, seguindo as propostas de Lollis e de Pellegrini opta pelo verbo, que parece levantar menos problemas quanto à cadência e compreensão do texto.

${ }^{39}$ LP 56,14. 
mesma: a ausência destes magnates do início da campanha militar do ano seguinte, tema que o rei aproveita como leit-motiv do cantar no refrão "non ven al maio". Ficam alguns exemplos ilustrativos da última sátira guerreira do monarca castelhano:

O que da guerra levou cavaleiros e a sa terra foi guardar dinheiros, non ven al maio.

O que da guerra se foi com maldade

[e] a sa terra foi comprar erdade, non ven al maio.

O que tragia o pendon sen tenda, per quant' agora sei de sa fazenda, non ven al maio.

$\mathrm{O}$ que se foi con medo dos martinhos e a sa terra foi bever los vinhos, non ven al maio.

O que, con medo, fugiu da fronteira, pero tragia pendon sen caldeira, non ven al maio.

O que [ar] roubou os mouros malditos e a sa terra foi roubar cabritos, non ven al maio. ${ }^{40}$

A referência a levar cavaleiros, ao pendão, à tenda ou à caldeira, nos dois últimos casos para assinalar a sua falta, coloca-nos perante uma crítica à mais alta nobreza castelhana que, sendo acusada de acções menos dignificantes na campanha anterior - nomeadamente a de se apresentar sem os cavaleiros estipulados ou ausentando-se da guerra demasiado cedo, uma vez recebidos os "dinheiros" -, se preparava para faltar à seguinte.

Ao contrário dos cantares anteriores, ambas as sátiras colectivas não parecem já conter os elementos que vimos mais associados à guerra andaluza dos anos sessenta, com genetes e coteifes em grande destaque. Agora, a crítica não incide tanto na cavalaria vilã ou numa nobreza porventura mais

${ }^{40}$ PAREDES XLII, estrofes I, II, VIII-XI. 
secundária, parecendo afectar prioritariamente a alta nobreza. Ou seja, o ambiente deverá aproximar-se mais do contexto do difícil relacionamento régio com as principais linhagens do reino, que se tinha começado a desenhar em 1269 mas que se institucionalizará sobretudo a partir de 1272. Precisamente neste ano, a Crónica de Alfonso $X$ reportava o pedido régio para que os magnates acompanhassem o infante herdeiro numa incursão contra Granada; estes, tendo já recebido quantias para o efeito, recusaram-se a servi-lo:

E demás, vos sabedes que el rey estando en Murçia que vos enbió dezir de cómmo lor moros fazían guerra, e que pues avíades tomado sus dineros, que vos mandava e rogava que fuésedes estar en aquella guerra con el infante don Ferrando, su fijo, e vos non lo quisistes fazer... ${ }^{41}$

Ao mesmo contexto pertenceriam, certamente, vários cantares de Pero Gomes Barroso, um dos trovadores galego-portugueses que acompanhou o rei nestas diatribes, em que o que está em causa é precisamente a ausência dos ricos-homens do campo de batalha ${ }^{42}$. Numa delas, Chegou aqui Don Foão e veo mui ben guisado, vemos um magnate a chegar, todo apetrechado para a guerra, supõe-se, mas com um detalhe irónico, o de chegar na altura errada: "non veo eno maio nen veo a Pintecoste". A primeira parte deste verso, repetida em todas as estrofes, reenvia directamente para o refrão da última composição de Afonso X, sinalizando um mesmo contexto de produção. Não deve causar admiração. O próprio Pero Gomes participou, do lado régio, na tentativa de resolução do diferendo que opunha o Sábio e a nobreza rebelde. A mesma Crónica de Alfonso $X$ regista o encontro entre o mestre de Calatrava e Pero Gomes, de um lado, e o rei de Granada e os nobres, do outro, em Alcalá de Bensaíde, numa primeira reunião tendente à solução do conflito em curso ${ }^{43}$. Nessa altura, Pero Barroso seria já pessoa

${ }^{41}$ CAX cap. XXXI e nota 151 . De acordo com o itinerário do monarca, este passou uma larga estadia em Múrcia entre 21 de Março de 1271 a 15 de Junho de 1272. O pedido poderia ter sido feito, portanto, antes da primavera de 1272, altura em que se terá verificado a incursão na Andaluzia. Para o percurso de Afonso X veja-se GONZÁLEZ JIMÉNEZ, M. e CARMONA RUIZ, M. Antonia - Documentación ..., cit., p. 711.

${ }^{42}$ Nomeadamente em Sei eu un ricome, se Deus mi pardon; Un ricome que oj' eu sei; Chegou aqui Don Foão e veo mui ben guisado. Cf., respectivamente LP 127,11; 127,13; 127,2 .

${ }^{43}$ CAX cap. LI. 
de idade, porquanto nascera antes do casamento de Gomes Viegas de Basto, seu pai, com Mor Rodrigues de Candarei. Como Rui Gomes Barroso, um dos filhos deste matrimónio, terá sido abade do mosteiro de Pombeiro cerca de 1222, podemos admitir que o trovador terá nascido por volta de 1200 ou, o mais tardar, alguns anos depois ${ }^{44}$.

Para além de Pero Gomes, um outro trovador português acompanhou Afonso $\mathrm{X}$ nos cantares contra os vassalos que não se apresentavam na guerra, invocando mil e uma razões justificativas para essa ausência. Mas, ao contrário do Barroso, Gil Peres Conde, o autor em causa, somente se pode documentar em Castela a partir dos finais dos anos sessenta, sabendo-se que continuou activo no reinado de D. Sancho IV, no qual se queixa de não medrar quanto desejaria ${ }^{45}$.

Embora a presença da guerra seja quase uma constante nas suas cantigas, é em Non troux' estes cavaleiros aqui e em Tantas minguas achan a Don Foan que mais se aproxima da temática da ausência da alta nobreza nas campanhas militares da Andaluzia. A título de exemplo, na primeira, feita a um rico-homem chegado à corte fora do tempo da actividade militar, vai nomeando tudo aquilo que ele não tinha trazido na altura própria:

Non troux' estes cavaleiros aqui este ricome nunca na guerra, que ora trage; son doutra terra, ca já eu [en eles] mentes meti; nen seus sinaes nonos conhosco, ca lhis dissera: - Bon dia vosco; mais neun [deles] eu non conhoci.

${ }^{44}$ Cf. PIZARRO, José Augusto de Sotto Mayor - Linhagens Medievais Portuguesas. Genealogias e estratégias (1279-1325). Porto: 1999, vol. 2, p. 29. Neste contexto, seria difícil que fosse ele o Pero Gomes Barroso documentado em 1296, que aparece, além do mais, identificado como castelhano (veja-se RON FERNÁNDEZ, Xabier - Carolina Michaëlis e os trobadores representados no 'Cancioneiro da Ajuda' in BREA, Mercedes (coord.) - Carolina Michaëlis e o Cancioneiro da Ajuda, hoxe. Santiago de Compostela: Centro Ramón Piñeiro e Xunta de Galicia, 2005, p. 163). Sabemos, por outro lado, que o nome do autor andou associado a figuras eclesiásticas de algum relevo a partir de finais do século. Cf. GAIBROIS DE BALLESTEROS, Mercedes - Sancho IV de Castilla. 3 vols. Madrid: 1922-1928, vol. I, p. 26 e 50.

${ }^{45}$ Se se referir a este rei, como penso, a sátira Ben sabedes, senhor Rei, cujo refrão é claro sobre o pensamento do autor: "non foi vosco en ora bõa". Cf. LP 56,3. 


\begin{abstract}
Nen estas armas eu nunca lhas vi trager na guerra; destes sinaes que ora trage, non trouxe taes nosco na guerra, quand' el-Rei foi i; nen outras por que as ar faria, senon quae-las ante tragia? E já sobr' esto con muitos departi. ${ }^{46}$
\end{abstract}

Menos seguro é o enquadramento de Pôs conta el-Rei en todas fronteiras, composição onde quem está em causa são os concelhos e os cavaleiros. Pelos rostos da sátira, pensaríamos talvez nos conflitos de meados dos anos sessenta, altura em que os concelhos estão mais na mira destas composições, mas faltam-nos indicações documentais sobre o início da presença do autor em Castela e, além disso, o papel militar de cavaleiros e concelhos manteve-se em tempos posteriores. A segunda estrofe resume a crítica, que no caso vertente incide sobre o facto de cavaleiros e milícias urbanas parecerem andar afastados do tipo de alimentação adequado para feitos bélicos:

A concelhos e a cavaleiros mandam comer vacas e carneiros, mais non cômian galinhas na guerra; ca diz que dizen os aguireiros que será perdimento da terra. ${ }^{47}$

Regressando aos últimos cantares de Afonso X, apenas em $O$ que foi passar a guerra encontramos referências concretas à fronteira, por intermédio de Granada e da respectiva veiga. Mas esta menção, em contexto interrogativo, parece surgir mais como exemplo das guerras de fronteira do que remeter para uma circunstância concreta. Se assim fosse e, por outro lado, se implicasse a presença do próprio Afonso X, deveria pensar-se nos anos em que o rei surge na famosa veiga de Granada, isto é, em 1265 ou em 1281. Parecendo remeter, no entanto, apenas para um momento de maior actividade militar na fronteira andaluza, é inegável que os anos setenta, a partir de 1272, seriam a altura indicada para a produção do cantar. Talvez próximo, mais uma vez, daquele fatídico ano de 1272, quando algumas das

\footnotetext{
${ }^{46}$ LP 56,10.

${ }^{47}$ LP 56,12. Foi retirado o acento em "agùireiros" na presunção de se tratar de uma gralha da edição de Lapa que foi mantida na edição utilizada neste estudo.
} 
mais sonantes linhagens castelhanas, como os Haro, os Lara e os Castro, decidiram, precipitar uma ruptura com o rei, não responder ao chamamento para o apoio militar ao infante D. Fernando e acolher-se junto do rei de Granada $^{48}$. O momento ideal, enfim, para o tom acre do Sábio nestes cantares, comparável ao que usa na carta que envia ao filho em $1273^{49}$. Deste modo, em relação a $O$ que foi passar a serra e a $O$ que da guerra levou cavaleiros, seguimos a proposta que, em seu tempo, López-Aydillo tinha avançado relativamente à segunda composição, situando-a em 1272 e ligando-a ao processo de afastamento das principais linhagens castelhanas para Granada, contexto que parece acomodar-se melhor às críticas presentes nestes cantare ${ }^{50}$. Mais recentemente, Vicente Beltrán procurou igualmente associá-las à revolta nobiliárquica, apesar de alguma indecisão quanto a O que foi passar a serra ${ }^{51}$.

Em conclusão, a reavaliação dos cantares bélicos do Sábio - em ligação com a reinterpretação de alguns desses cantares, o conhecimento do período em estudo ou documentação coeva - permitiu não só definir melhor o conjunto das composições a integrar na temática em causa, mas também distender mais no tempo a sua produção.

Esta ter-se-á iniciado ainda antes de 1252, com uma sátira ao seu irmão D. Henrique, onde, de acordo com a interpretação dada ao cantar em causa,

${ }^{48}$ Sobre o contexto e as reivindicações nobiliárquicas vejam-se ESCALONA, Julio Los nobles contra su rey. Argumentos y motivaciones de la insubordinación nobiliaria de 1272-1273. Cahiers de linguistique et civilisation hispaniques médiévales. 25 (2002), p. 131-162, e ALONSO, Isabel - Desheredamiento y desafuero, o la pretendida justificación de una revolta nobiliaria. Cahiers de linguistique..., cit., 25 (2002), p. 99-129.

${ }^{49}$ CAX cap. LII.

${ }^{50}$ LÓPEZ-AYDILLO, Eugenio - Los cancioneros gallego-portugueses como fuentes históricas. Revue Hispanique, 132 (Abril de 1923), p. 422-425. Na p. 426 este autor, após lembrar a participação de Pero Gomes Barroso nas conversações com os magnates castelhanos, situa no mesmo contexto uma outra composição deste trovador português (LP 127,5) em que ele se vangloria de trazer de Granada "o our' e o mouro".

${ }^{51}$ Esta associação, no entanto, foi feita no contexto da tentativa de construção de um largo ciclo satírico à volta dos "nobles rebeldes" ao qual tenho dificuldades em aderir, quer por falta de elementos de apoio credíveis em muitas das composições elencadas, quer por interpretações que não consigo acompanhar. Veja-se BELTRAN, Vicenç - Los nobles rebeldes in IDEM - Poética, poesía y sociedad en la lírica medieval. Santiago de Compostela: Universidade de Santiago de Compostela, 2007, p. 13-52. 
o então infante terá imaginado o hilariante exército que o fiel mordomo do rei D. Fernando poderia disponibilizar para auxiliar o irmão nos conflitos que se instalaram na corte após a conquista de Sevilha ${ }^{52 .} \mathrm{O}$ aproveitamento da actividade militar em âmbito trovadoresco somente regressaria, mas aí em força, no contexto da revolta mudéjar de 1264, altura em que os genetes muçulmanos e os coteifes cristãos, positiva ou negativamente, ganharam alguma notoriedade na sátira então produzida. Após as quatro composições situadas pelos anos 1264-1265, as perturbações originadas pela revolta da alta nobreza nos anos de 1272-273 e o próprio comportamento dos nobres na altura terão suscitado, enfim, a produção de duas sátiras violentas em que é vituperada a defecção dos grandes do reino do serviço militar que deveriam prestar ao rei no contexto da ameaça muçulmana que se desenhava na Andaluzia. Terão sido os últimos cantares com fundo militar compostos pelo rei, pelo menos dos que chegaram até nós preservados pelos cancioneiros. Finalmente, a releitura destas composições permitiu afastar deste núcleo três cantigas dirigidas a dois nobres galegos, Pero Garcia Galego e Mem de Candarei, que, quer por um enquadramento militar algo difuso, quer pelo tratamento que nelas é dado aos dois visados, as dissocia de uma maneira clara das restantes.

\section{Apêndice: os cantares da guerra de D. Afonso X}

1248-52 Don Rodrigo moordomo que ben pos al Rei a mesa

1264-66 Vi un coteife de mui gran granhon

O genete

Domingas Eanes ouve sa baralha

Don Foan, quand'ogano i chegou

1972-73 O que foi passar a serra

O que da guerra levou cavaleiros

${ }^{52}$ Cf. O’ CALLAGHAN, Joseph F. - El Rey Sabio..., cit., p. 104-107 e GONZÁLEZ JIMÉNEZ, M. - Alfonso X..., cit., p. 81-85. 